\author{
I.Yu. Silachyov \\ Institute of Nuclear Physics, Almaty, Kazakhstan \\ e-mail: silachyov@inp.kz
}

\title{
Instrumental neutron activation analysis of rhenium in uranium raw material
}

\begin{abstract}
The application of comparator instrumental neutron activation analysis combined with the internal standard method was considered to study rhenium content of the uranium raw material core samples collected in Chu-Sarysu uranium province in the Southern Kazakhstan. Iron content of the samples as the internal comparator was determined by X-ray fluorescence analysis with the help of a laboratory energy dispersive X-ray spectrometer. Rhenium was analyzed by its long-lived radionuclide ${ }^{186} \mathrm{Re}$ using a planar type HPGe detector. Six certified reference materials of complex ores and nonferrous metal concentrates were analyzed to verify the accuracy of the method. Rhenium and its main interfering elements were determined in the samples from three different sites of the uranium province. Due to reverse correlation dependence, selenium was found as a simple predictor of industrially significant rhenium contents. The method can be used to analyse rhenium mass fractions more than $\approx 0.02$ $\mathrm{mg} / \mathrm{kg}$ in the ores with uranium content of the samples not exceeding several hundreds $\mathrm{mg} / \mathrm{kg}$.
\end{abstract}

Key words: Neutron activation analysis, internal standard, rhenium, uranium ore.

\section{Introduction}

Rhenium, a valuable element for modern industry, belongs to the scattered element group and does not form its own deposits. Main raw material sources of rhenium by-product extraction in the world are molybdenum, copper-molybdenum porphyry ores and cupreous sandstones [1, 2]. Alternative rhenium industrial sources include copper pyrite and copper nickel fields, carbonaceous rocks, coals, liquid carbohydrates and some other objects [3]. In recent times the "blanket oxidation zone deposits" or "sandstone type deposits" were related to an important non-traditional rhenium source [2]. Such zones are well known in the world due to localization of the bedded infiltration uranium deposits which are worked out everywhere by underground leaching [4]. In Kazakhstan the numerous sandstone uranium deposits are localized within the Near Tien Shan uranium mega-province including Chu-Sarysu and Syr Darya uranium basins $[5,6]$. Uranium ores of the province are distinguished by their complex character and contain a range of rare elements, but mainly in low contents.

Rhenium content in the Southern Kazakhstan uranium basins corresponds to sundry degree of knowledge. The study for associated elements during uranium deposit exploration was carried out in different time (including several decades ago), by the methods differing in their sensitivity, using individual or combined core samples. In some deposits rare elements were not determined at all [7]. However, in view of the continuing search and exploration of new uranium fields by JSC "NAC Kazatomprom" to promote uranium branch in Kazakhstan, development of simple up-to-date methods of rhenium analysis became vital now to predict the scopes of its by-product production.

A lot of methods of rocks and mineral raw material analysis for rhenium content are known at present [8]. Most of them suffer from insufficient sensitivity and poor selectivity. To overcome these disadvantages sample decomposition with subsequent rhenium preconcentration and separation from the matrix is used in spectrophotometric methods and X-ray fluorescence (XRF) analysis [8, 9]. Widely used inductively coupled plasma atomic emission spectrometry offers better sensitivity, but rhenium analytical lines are partly overlapped with the lines of concomitant elements $[10,11]$. Mass spectrometry with inductively coupled plasma (ICPMS) is one of the most sensitive methods of rhenium determination, but this advantage can be reached only after rhenium quantitative separation of the matrix using some way or another [12-14]. 
Moreover, ICP-MS is usually affected by matrix effects, isobaric interferences and signal drift.

Sample decomposition with subsequent rhenium preconcentration additionally complicated by high volatility of rhenium compounds is the most serious drawback of all the methods above. In this respect non-destructive neutron activation analysis as one of the most sensitive methods of trace element determination is an attractive option. However, the application of its instrumental variant (INAA) is restricted by low rhenium contents of geological samples and high matrix activity. Preliminary rhenium concentration can be used in this case [15, $16]$, but the necessity in supra pure reagents makes the method not in current use. Radiochemical neutron activation analysis (RNAA) based on ionexchange chromatographic separation is far more prevalent, when rhenium is determined together with platinum group elements [17-19].

In this work comparator INAA using the XRFbased internal standard method and iron content of the samples as the internal comparator $[20,21]$ was tried to analyze rhenium content of the uranium ore core samples collected from several sites of the ShuSarysu uranium province in the Southern Kazakhstan.

\section{Materials and methods}

A great number of grinded ore samples studied by gamma-ray spectrometric method were preliminary inspected. The samples with the uranium content of no more than $\approx 300 \mathrm{mg} / \mathrm{kg}$ were selected based on the previous experience [22] to prevent counting and other problems. The chosen samples were then analyzed by XRF technique using an energy dispersive spectrometer RLP-21T by JSC “AspapGeo" (Almaty, Kazakhstan) for iron mass fraction as an internal standard to realize comparator INAA [20]. The spectrometer was designed to analyze rocks, ores, concentrates and so on. The accuracy of its software was repeatedly confirmed with the help of different corresponding certified reference materials (CRMs). The ascribed uncertainty of iron content measuring in rock samples is $2-8 \%$. RLP-21T is enrolled in the State Register of Measuring Devices, and the corresponding analytical technique is registered by the National Body for Certification of Kazakhstan.

INAA of the same samples for rhenium and some other element contents by the long-lived radionuclides was then carried out. About $100 \mathrm{mg}$ of the assays divided into several parties were sealed in small thin double polyethylene bags and packed in aluminium foil. There wasn't any need in sample precise weighing using an analytical balance since an independent method to determine the internal comparator content was applied. Every package included ten samples and a zirconium monitor to evaluate epithermal to thermal neutron flux ratio (10 $\mathrm{mg}$ of $\mathrm{ZrO}_{2}$ ). Package length was about $10 \mathrm{~mm}$.

All the packages were irradiated in different days for 2.5 hours in the position № 4 inside the water channel № 10-6 of the research reactor WWR-K by thermal neutron $(<0.625 \mathrm{eV})$ flux density $8.9 \times 10^{13} \mathrm{~cm}^{-2} \mathrm{~s}^{-1}$; the fast neutron $(0.1-1.15$ $\mathrm{MeV}$ ) flux density amounted to $6.0 \times 10^{12} \mathrm{~cm}^{-2} \mathrm{~s}^{-1}$ [23]. To reduce the influence of neutron flux gradient, the packages were oriented along the channel axis.

Direct rhenium determination by the long-lived radionuclide ${ }^{186} \mathrm{Re}$ in rocks is highly impeded by substantial spectral interferences from hafnium, selenium and sometimes from other elements (ytterbium). Since ${ }^{186} \mathrm{Re}$ spectrum is characterized by the single analytical gamma-line, its count rate can be hardly measured correctly using a coaxial type semiconductor detector due to its insufficient resolution. That is why a planar type detector was preferred notwithstanding its far lower total efficiency.

The irradiated samples were counted by a planar HPGe detector GLP36360 with the crystal dimensions $36 \times 13 \mathrm{~mm}$ and an energy resolution of $585 \mathrm{eV}$ at the $122 \mathrm{keV}$ peak of ${ }^{57} \mathrm{Co}$ connected to an ORTEC multi-channel analyzer DSPEC LF. Spectra collection was carried by the MAESTRO software. Detector calibration for relative detection efficiency was made with the help of a multi-gamma ray standard $\left({ }^{152} \mathrm{Eu},{ }^{154} \mathrm{Eu},{ }^{155} \mathrm{Eu}\right)$ and an isotopic source ${ }^{133} \mathrm{Ba}$, both by Canberra. Before measuring rhenium content of the samples, 9-12 days of the decay time elapsed to make radionuclide ${ }^{24} \mathrm{Na}$ almost completely decayed and Compton background from uranium fission products essentially reduced. This made possible to use very close counting geometry $-10 \mathrm{~mm}$ to the detector cap. The approximate time of spectra collection was 30-60 minutes. The first counting was also used to evaluate ytterbium and uranium contents. The samples were counted once again a fortnight later to determine selenium and hafnium mass fractions.

Spectra treatment was carried out by the "AnalGamma" software developed in the Institute of Nuclear Physics to provide gamma-ray spectrometric analysis. The software approximates a part of gamma-ray spectrum in the treatment 
window by Gaussian curves and a flat background and calculates peak count rates $J$ in cps. Partly overlapping peaks can be reliably resolved. Quality of the approximation is checked by the $\chi^{2}$ test. Then the other software converts $J$ values of the analytical peaks into the element contents $C_{a}$ of the samples.
$C_{a}$ values (\%) were calculated according to the next model based on the single comparator method (SCM) of standardization [24] using the internal standard method [20] (lower case indices $a$ and $c$ mean an analyzed element and the comparator, respectively):

$$
C_{a}=C_{c} \frac{k_{c} N_{p, a} \varepsilon\left(E_{c}\right)\left(f+Q_{0}^{c}\right)(S D C)_{c} G_{c} F_{c}}{k_{a} N_{p, c} \varepsilon\left(E_{a}\right)\left(f+Q_{0}^{a}\right)(S D C)_{a} G_{a} F_{a}} K_{a, c}
$$

where $C_{c}$ is the element comparator content of the sample (\%), $N_{p}$ is net peak area of the measured gamma-line (cps), $\varepsilon(E)$ is the relative detection efficiency of the measured gamma-line (\%), $Q_{0}$ is the resonance integral $I_{0}\left(\mathrm{~cm}^{2}\right)$ to thermal neutron cross-section $\sigma_{0}\left(\mathrm{~cm}^{2}\right)$ ratio, $f$ is the thermal to epithermal neutron flux ratio, $S=1-\exp \left(-\lambda t_{i r r}\right)$ is saturation factor, $D=\exp \left(-\lambda t_{d}\right)$ is decay factor, $C=\left(1-\exp \left(-\lambda t_{m}\right)\right) / \lambda t_{m}$ is the counting factor $\left(t_{i r r}, t_{d}\right.$, and $t_{m}$ are irradiation, decay and measuring time), $G$ is the correction factor for neutron self-shielding by the sample, $F$ is the correction factor for analytical gamma-ray self-absorption by the sample, and the $k$ factor is composed of nuclear constant product:

$$
k=\sigma_{0} \theta P_{\gamma} M^{-1},
$$

where $\theta$ is isotopic abundance (\%), $P_{\gamma}$ is the yield of the measured gamma-line (\%), $M$ is the atomic mass (Da).

The empirical correction factor $K_{a, c}$ accessed by the CRMs is used to compensate for a bias caused by the errors of the detector calibration and other reasons and to adjust the model for the specific counting geometry. That is why there is no need both in $\alpha$-parameter to correct $I_{0}$ for nonideal epithermal neutron flux distribution, and in $J$ correction for true coincidences.
Correction factors $G$ is ignorable for the $100 \mathrm{mg}$ uranium ore samples not distinguished by high contents of rare earths or other elements with anomalous $\sigma_{0}$ values. Coefficient $F$ is very close to unity in case of rock analysis since there is no appreciable self-absorption of ${ }^{186} \mathrm{Re}$ analytical gamma-line $(137.16 \mathrm{keV})$ in a thin $(<1 \mathrm{~mm})$ light source such as an aluminum-siliceous matrix.

The model ratio of $1 / f$ was evaluated by the "bare bi-isotopic method" [25] with the help of a monitor of the neutron flux spectral composition - a $\mathrm{ZrO}_{2}$ sample [20]:

$$
\begin{gathered}
\frac{1}{f}=\frac{\sigma_{0.2}-B \sigma_{0.1}}{B I_{0.1}-I_{0.2}}, \\
B=\frac{N_{p, 2} \varepsilon\left(E_{1}\right) \theta_{1} P_{\gamma, 1}(S D)_{1}}{N_{p, 1} \varepsilon\left(E_{2}\right) \theta_{2} P_{\gamma, 2}(S D)_{2}},
\end{gathered}
$$

where lower indices 1 and 2 correspond to two $\mathrm{Zr}$ isotopes $\left(Q_{0.1}<<Q_{0.2}\right)$. $C$ factor in Eq. 3 is ignorable due to a very short counting time. The ratio can be simply reevaluated for every irradiation. During the investigation the resonance to thermal neutron flux ratio in the irradiation position varied within 0.028 0.034 .

Table 1 - Main nuclear data used to calculate rhenium, its interfering elements and uranium by comparator INAA

\begin{tabular}{|c|c|c|c|c|c|c|c|}
\hline $\begin{array}{c}\text { Activated } \\
\text { isotope }\end{array}$ & $\begin{array}{c}\text { Isotopic } \\
\text { abundance, } \%\end{array}$ & $\sigma_{0}, \mathrm{~cm}^{2}$ & $I_{0}, \mathrm{~cm}^{2}$ & $\begin{array}{c}\text { Target } \\
\text { radionuclide }\end{array}$ & $\begin{array}{c}\text { Half-life, } \\
\text { days }\end{array}$ & $\begin{array}{c}\text { Energy, } \\
\text { keV }\end{array}$ & $\begin{array}{c}\text { Quantum } \\
\text { yield, \% }\end{array}$ \\
\hline${ }^{185} \mathrm{Re}$ & 37.4 & 110 & 1694 & ${ }^{186} \mathrm{Re}$ & 3.72 & 137.16 & 9.47 \\
\hline${ }^{74} \mathrm{Se}$ & 0.89 & 51.8 & 545.4 & ${ }^{75} \mathrm{Se}$ & 119.8 & 136.00 & 58.3 \\
\hline & & & & & & 133.02 & 43.3 \\
${ }^{180} \mathrm{Hf}$ & 35.2 & 13.5 & 34 & ${ }^{181} \mathrm{Hf}$ & 42.39 & 136.26 & 5.85 \\
& & & & & & 136.86 & 0.86 \\
\hline${ }^{174} \mathrm{Yb}$ & 31.8 & 63.4 & 29.2 & ${ }^{175} \mathrm{Yb}$ & 4.19 & 396.33 & 13.2 \\
\hline${ }^{238} \mathrm{U}$ & 99.28 & 2.68 & 277 & ${ }^{239} \mathrm{~Np}\left({ }^{239} \mathrm{U}\right)$ & 2.36 & 277.60 & 0.144 \\
\hline${ }^{58} \mathrm{Fe}$ & 0.28 & 1.28 & 1.25 & ${ }^{59} \mathrm{Fe}$ & 44.50 & 192.34 & 3.08 \\
\hline
\end{tabular}


The main nuclear data used to calculate rhenium content (including iron as the internal standard) and to evaluate interfering element contents are presented in Table 1 [26]. ${ }^{181} \mathrm{Hf}$ and ${ }^{175} \mathrm{Yb}$ spectral interferences to ${ }^{186} \mathrm{Re}$ are tabulated as well. Uranium was enrolled too since its mass fraction is one of the basic restrictions of the approach.

\section{Results and discussion}

To assess accuracy of rhenium determination by comparator INAA, several CRMs of complex ores and non-ferrous metal concentrates certified for rhenium content were used (Table 2). OSO 528 was produced by the All-Russian Scientificresearch Institution of Mineral Resources (FSBI VIMS), Moscow, and the other five - by JSC "Tsentrgeolanalit", Republic of Kazakhstan. The CRM samples were prepared, irradiated and analyzed as described above. To avoid overirradiation and diminish gamma-ray selfabsorption, the sample mass of concentrate and uranium ore CRMs was diminished to $30-50 \mathrm{mg}$. A single measurement of each CRM was carried out.

The first three CRMs are characterized by rather low content of the main elements impeding rhenium determination. ${ }^{186} \mathrm{Re}$ analytical gamma-line is distinctly resolved from a ${ }^{75} \mathrm{Se}$ gamma-line (136.00 $\mathrm{keV}$ ) and from a rather intensive ${ }^{181} \mathrm{Hf}$ gamma-line $\left(136.26 \mathrm{keV}, P_{\gamma}=5.85 \%\right)$. Contribution of a 136.26 $\mathrm{keV}$ low-intensive ${ }^{181} \mathrm{Hf}$ gamma-line $\left(P_{\gamma}=0.86 \%\right)$ is simply taken into account with another one (133.02 $\left.\mathrm{keV}, P_{\gamma}=43.3 \%\right)$. Corrections to ${ }^{186} \mathrm{Re}$ count rate
$(137.16 \mathrm{keV})$ appeared rather small, within 1.5$3.5 \%$. The same is true for OSO 528 too, but a partly resolved low-intensive gamma-line of ${ }^{175} \mathrm{Yb}$ $\left(137.66 \mathrm{keV}, P_{\gamma}=0.235 \%, C_{\mathrm{Yb}}=40.2 \mathrm{mg} / \mathrm{kg}\right)$ in the spectrum of this CRM with the enhanced rare-earth contents makes the result less reliable.

The samples of concentrates are practically deprived of hafnium and selenium according to their gamma-spectra but contain high contents of heavy metals: $61 \%$ of lead in GSO 2890 and $40.4 \%$ of copper in GSO 2891, both apart from some minor contents of another heavy elements. For these CRMs the self-absorption correction (Eq. 1) was estimated in the approximation of a thin irradiating layer:

$$
\frac{F_{c}}{F_{a}}=\frac{\mu\left(E_{a}\right)\left(1-\exp \left(-\rho \mu\left(E_{c}\right) d\right)\right.}{\mu\left(E_{c}\right)\left(1-\exp \left(-\rho \mu\left(E_{a}\right) d\right)\right.},
$$

where $\mu(E)$ is photon mass attenuation coefficient $\left(\mathrm{cm}^{2} \mathrm{~g}^{-1}\right) ; \rho$ is sample density $\left(\mathrm{g} \mathrm{sm}^{-3}\right)$ and $d$ is sample thickness (cm). $\mu(E)$ values of ${ }^{186} \mathrm{Re}$ and ${ }^{59} \mathrm{Fe}$ analytical gamma-lines in different matter were picked up from a NIST database [27]. Sample bulk density having been independently evaluated, the self-absorption correction appeared about $10 \%$ in case of lead concentrate analysis and no more than $1 \%$ for copper one. Such moderate corrections resulted from both application of the internal standard method and not too far difference between $E_{a}(137.16 \mathrm{keV})$ and $E_{c}(192.34 \mathrm{keV})$.

Relative expanded uncertainty of the INAA results was estimated as follows $(P=0.95)$ :

$$
\frac{U\left(C_{a}\right)}{C_{a}} \approx 2 \sqrt{\frac{u\left(J_{a}\right)^{2}}{J_{a}{ }^{2}}+\frac{u\left(J_{c}\right)^{2}}{J_{c}{ }^{2}}+\frac{u\left(C_{c}\right)^{2}}{C_{c}{ }^{2}}+s_{a}{ }^{2}},
$$

where $u\left(J_{a}\right), u\left(J_{c}\right)$, and $u\left(C_{c}\right)$ are standard uncertainties of the corresponding values as in Eq. $1, s_{a}$ is the standard deviation of element analysis (methodical uncertainty) by SCM (all the ratios and $s_{a}$ are in \%). The last value assessed earlier with the help of the CRMs equals $\approx 4 \%$. Standard uncertainty of iron internal comparator content of a sample by XRF corresponded to the ascribed values according to the certified analytical technique.

The results of CRM analyses for rhenium content by comparator INAA using Eq. 1 and Eq. 2 $(P=0.95)$ are presented in Table 2 . Iron content of the samples was determined by XRF. The measured values are well comparable with the certified ones with $<4 \%$ of discrepancy.

On the other hand, $E_{\mathrm{n}}$-number usually used as a recommended by IUPAC criterion to verify laboratory performance [28] also showed good agreement between all certified and measured values within acceptable value \pm 1 (Table 2).

So the demonstrated accuracy of rhenium determination in a range of CRMs by comparator INAA enabled to try this approach for real geological samples. 
Table 2 - Rhenium content of CRMs by comparator INAA using iron as the internal standard $(P=0.95)$

\begin{tabular}{|c|c|c|c|c|c|}
\hline CRM & \multirow{2}{*}{$\begin{array}{c}\text { CRM type } \\
\text { number }\end{array}$} & \multirow{2}{*}{ Fe, $\%$} & \multicolumn{2}{|c|}{ Re, mg/kg } & \multirow{2}{*}{$E_{\mathrm{n}-\text { number }}$} \\
\cline { 4 - 6 } & & & Certified value & Measured value & \\
\hline GSO 3029 & Copper porphyritic ore & $2.99 \pm 0.17$ & $0.43 \pm 0.02$ & $0.430 \pm 0.044$ & 0 \\
\hline GSO 3030 & Copper molybdemum scarn ore & $13.61 \pm 0.45$ & $0.30 \pm 0.02$ & $0.291 \pm 0.030$ & -0.25 \\
\hline GSO 3031 & Copper molybdemum scarn ore & $15.31 \pm 0.45$ & $0.40 \pm 0.03$ & $0.394 \pm 0.040$ & -0.12 \\
\hline OSO 528 & Phosphorus rare earth uranium ore & $15.53 \pm 0.45$ & $0.79 \pm 0.04$ & $0.82 \pm 0.11$ & 0.26 \\
\hline GSO 2890 & Lead concentrate & $1.393 \pm 0.081$ & $21.4 \pm 1.0$ & $21.2 \pm 2.8$ & 0.13 \\
\hline GSO 2891 & Copper concentrate & $5.84 \pm 0.30$ & $28.2 \pm 1.2$ & $27.8 \pm 3.3$ & -0.11 \\
\hline
\end{tabular}

Tables 3-5 presents the results of rhenium and two its main interfering element contents by comparator INAA $(P=0.95)$ of the uranium ore core samples collected from three different sites of the Shu-Sarysu uranium province. Ytterbium contents as a possible interfering element were evaluated as well. Iron mass fractions by XRF are presented with the ascribed uncertainties corresponding to the certain intervals of iron contents. Uranium mass fraction was determined by its daughter long-lived radionuclide ${ }^{239} \mathrm{~Np}$ using iron content of the samples, as the other elements.

Eight of ten samples from site I (Table 3) revealed rhenium contents up to $0.3 \mathrm{mg} / \mathrm{kg}$. Low mass fraction of the interfering elements not far differing from their Clarke (crust average) contents didn't hinder from rhenium determination. In two samples, with selenium contents exceeding its Clarke value $(0.05 \mathrm{mg} / \mathrm{kg})$ by three orders of magnitude, rhenium wasn't found. The upper assessment of rhenium content of these two samples approximately corresponds to its limit of identification (lowest content that can be safely detected, LOI) as double limit of detection (LOD) [29]. The latter was estimated in the way commonly used in spectroscopic methods: LOD $\approx$ three counting statistics of total background counts at the peak area.

Table 3 - Rhenium, uranium, internal standard, and interfering element content of the uranium ore samples from site I $(P=0.95)$

\begin{tabular}{|c|c|c|c|c|c|c|}
\hline $\begin{array}{c}\text { Sample } \\
\text { number }\end{array}$ & $\mathrm{Re}, \mathrm{mg} / \mathrm{kg}$ & $\mathrm{Se}, \mathrm{mg} / \mathrm{kg}$ & $\mathrm{Hf}, \mathrm{mg} / \mathrm{kg}$ & $\mathrm{Yb}, \mathrm{mg} / \mathrm{kg}$ & $\mathrm{U}, \mathrm{mg} / \mathrm{kg}$ & $\mathrm{Fe}, \%$ \\
\hline 556 & $0.059 \pm 0.009$ & $1.88 \pm 0.28$ & $3.35 \pm 0.33$ & $1.74 \pm 0.19$ & $170 \pm 17$ & $0.988 \pm 0.080$ \\
\hline 561 & $0.095 \pm 0.014$ & $<0.2$ & $2.72 \pm 0.29$ & $1.50 \pm 0.18$ & $188 \pm 19$ & $0.556 \pm 0.080$ \\
\hline 571 & $0.308 \pm 0.034$ & $<0.2$ & $6.00 \pm 0.53$ & $2.30 \pm 0.25$ & $187 \pm 19$ & $1.818 \pm 0.081$ \\
\hline 576 & $<0.02$ & $46.5 \pm 4.2$ & $3.00 \pm 0.30$ & $1.31 \pm 0.13$ & $304 \pm 30$ & $0.758 \pm 0.080$ \\
\hline 597 & $0.043 \pm 0.009$ & $<0.2$ & $1.37 \pm 0.15$ & $0.84 \pm 0.11$ & $199 \pm 20$ & $0.472 \pm 0.048$ \\
\hline 600 & $0.020 \pm 0.007$ & $0.21 \pm 0.07$ & $3.02 \pm 0.30$ & $1.84 \pm 0.23$ & $245 \pm 25$ & $0.619 \pm 0.080$ \\
\hline 608 & $0.174 \pm 0.023$ & $1.33 \pm 0.21$ & $2.93 \pm 0.29$ & $2.73 \pm 0.32$ & $234 \pm 24$ & $0.698 \pm 0.080$ \\
\hline 628 & $0.182 \pm 0.022$ & $<0.2$ & $6.27 \pm 0.61$ & $3.43 \pm 0.35$ & $106 \pm 11$ & $2.89 \pm 0.17$ \\
\hline 630 & $0.016 \pm 0.006$ & $1.90 \pm 0.30$ & $6.43 \pm 0.64$ & $3.58 \pm 0.35$ & $133 \pm 13$ & $3.07 \pm 0.17$ \\
\hline 649 & $<0.02$ & $198 \pm 19$ & $3.29 \pm 0.30$ & $1.36 \pm 0.13$ & $208 \pm 21$ & $0.654 \pm 0.080$ \\
\hline
\end{tabular}

Almost in all samples from site II (Table 4) rhenium contents appeared lower their LOI and accompanied by very high selenium contents, with the exception of № 316. As for site I, increased rhenium mass fraction of the sample agrees with selenium content lower LOI of the latter.

A part of gamma-ray spectrum of sample № 316 counted for 30 minutes after 10 days of decay is presented in Fig. 1 in a log-linear scale. It displays clearly that ${ }^{186} \mathrm{Re}$ background/peak ratio is quite enough to obtain reliable results in case of even far lower rhenium contents. This ratio substantially depends on the intensities of some gamma-lines of ${ }^{239} \mathrm{~Np}$ and the uranium fission products (including not shown in Figure 1). The dependence increases sharply with the uranium mass fraction growth. ${ }^{186} \mathrm{Re}$ half-life is comparable with that of ${ }^{239} \mathrm{~Np},{ }^{99} \mathrm{Mo},{ }^{140} \mathrm{La}$ and less than the half-lives of ${ }^{141} \mathrm{Ce},{ }^{147} \mathrm{Nd},{ }^{131} \mathrm{I}$, and ${ }^{140} \mathrm{Ba}$. That's why, to gain the best sensitivity, there should be a minimum decay time to make possible 
counting in a close geometry. Decay time is assessed empirically and in case of uranium content no more than $250 \mathrm{mg} / \mathrm{kg}$ begins from $8-9$ days, actually right after ${ }^{24} \mathrm{Na}$ has practically decayed.
${ }^{59} \mathrm{Fe}$ gamma-peak of sample № 316 $\left(\mathrm{C}_{\mathrm{Fe}}=2.31 \%\right)$ is not too expressed against background (Figure 1) but its count rate is enough to use it as the internal standard.

Table 4 - Rhenium, uranium, internal standard, and interfering element content of the uranium ore samples from site II $(P=0.95)$

\begin{tabular}{|c|c|c|c|c|c|c|}
\hline $\begin{array}{c}\text { Sample } \\
\text { number }\end{array}$ & $\mathrm{Re}, \mathrm{mg} / \mathrm{kg}$ & $\mathrm{Se}, \mathrm{mg} / \mathrm{kg}$ & $\mathrm{Hf}, \mathrm{mg} / \mathrm{kg}$ & $\mathrm{Yb}, \mathrm{mg} / \mathrm{kg}$ & $\mathrm{U}, \mathrm{mg} / \mathrm{kg}$ & $\mathrm{Fe}, \%$ \\
\hline 232 & $<0.03$ & $401 \pm 40$ & $3.40 \pm 0.34$ & $1.94 \pm 0.25$ & $202 \pm 20$ & $0.587 \pm 0.080$ \\
\hline 241 & $<0.03$ & $955 \pm 83$ & $5.21 \pm 0.52$ & $2.31 \pm 0.27$ & $115 \pm 12$ & $1.500 \pm 0.081$ \\
\hline 254 & $<0.05$ & $2460 \pm 220$ & $3.82 \pm 0.38$ & $1.48 \pm 0.19$ & $192 \pm 19$ & $1.161 \pm 0.081$ \\
\hline 265 & $<0.04$ & $968 \pm 97$ & $4.41 \pm 0.44$ & $1.73 \pm 0.21$ & $180 \pm 18$ & $1.180 \pm 0.081$ \\
\hline 268 & $<0.03$ & $265 \pm 23$ & $2.39 \pm 0.24$ & $1.81 \pm 0.19$ & $134 \pm 14$ & $6.39 \pm 0.30$ \\
\hline 291 & $<0.03$ & $420 \pm 42$ & $3.16 \pm 0.32$ & $1.36 \pm 0.18$ & $212 \pm 22$ & $0.855 \pm 0.080$ \\
\hline 304 & $<0.02$ & $173 \pm 16$ & $3.61 \pm 0.36$ & $1.77 \pm 0.19$ & $160 \pm 16$ & $2.60 \pm 0.17$ \\
\hline 308 & $<0.05$ & $2730 \pm 230$ & $1.67 \pm 0.25$ & $2.78 \pm 0.37$ & $162 \pm 17$ & $18.79 \pm 0.45$ \\
\hline 316 & $0.738 \pm 0.075$ & $<0.2$ & $5.81 \pm 0.51$ & $4.02 \pm 0.43$ & $142 \pm 14$ & $2.31 \pm 0.17$ \\
\hline 324 & $<0.03$ & $936 \pm 94$ & $2.29 \pm 0.26$ & $1.09 \pm 0.14$ & $1.77 \pm 0.19$ & $0.891 \pm 0.080$ \\
\hline
\end{tabular}

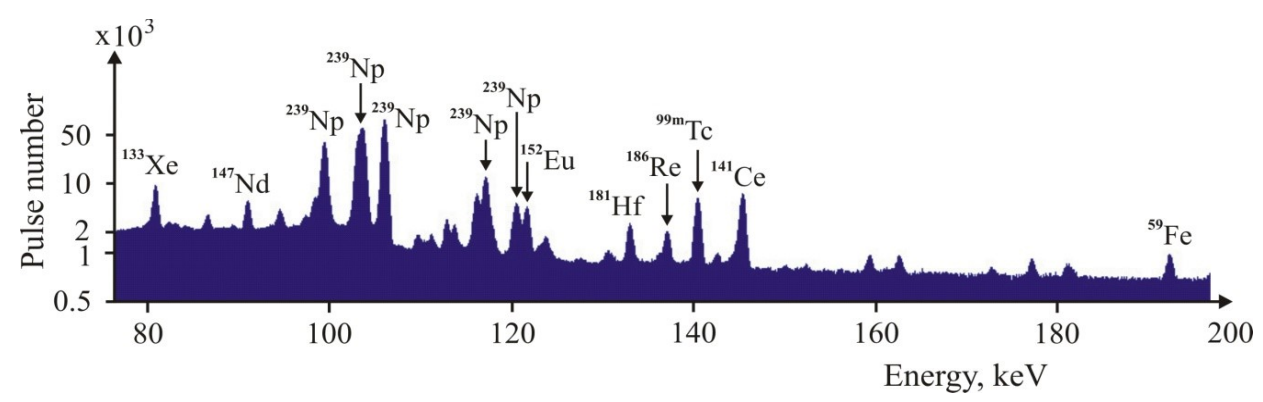

Figure 1 - A part of gamma-ray spectrum of uranium ore sample № 316 counted by GLP36360 (in log-linear scale)
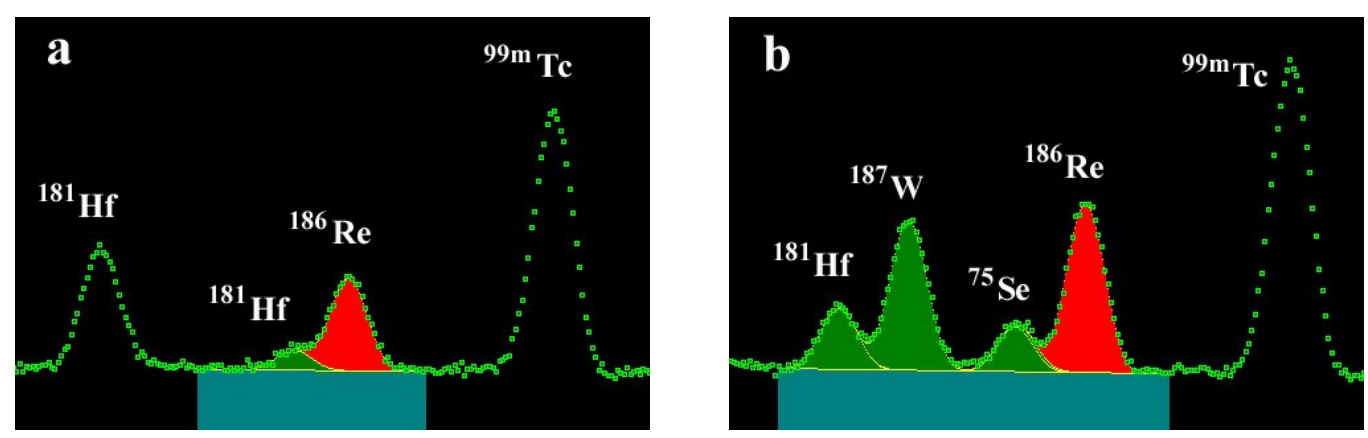

Figure 2 - net peak area of ${ }^{186} \mathrm{Re}$ and adjacent radionuclides in "AnalGamma" treatment window: sample № 316 (a) and № 10 (b)

The zoomed fragment of the spectrum № 316 in the vicinity of ${ }^{186} \mathrm{Re} 137.16 \mathrm{keV}$ gamma-line is shown in more details in Figure 2(a) in the treatment window of the "AnalGamma" software. Only rhenium and hafnium (136.26 keV) gamma-lines were approximated by Gaussian curves. The Int. j. biol. chem. (Online) treatment interval is marked by a different colour.

Site III (Table 5) appeared the most promising among the studied three with respect to the rhenium content. All the ten samples revealed surely quantitative rhenium mass fractions and two of them - more than $1 \mathrm{mg} / \mathrm{kg}$. Selenium content is lower its 
LOI or not too high comparing with the samples from site II.

Figure 2(b) presents the treatment area including rhenium gamma-line for the sample № 10 . The spectrum counted for 20 minutes after 8 days of decay is distinguished by a distinct gamma-line of ${ }^{187} \mathrm{~W}$ $(134.25 \mathrm{keV})$. This is an atypical situation since only several samples contained tungsten among the dozens of the investigated ones. The presence of ${ }^{187} \mathrm{~W}$ gammaline changed practically nothing, but in the cases of its much higher intensities the decay time should be apparently increased to get a reliable net peak area of ${ }^{181} \mathrm{Hf}$ (to take into account its contribution to ${ }^{186} \mathrm{Re}$ count rate). Rather moderate ${ }^{75} \mathrm{Se}$ gamma-line is surely resolved with the ${ }^{186} \mathrm{Re}$ one and doesn't hinder rhenium determination.

Table 5 - Rhenium, uranium, internal standard, and interfering element content of the uranium ore samples from site III $(P=0.95)$

\begin{tabular}{|c|c|c|c|c|c|c|}
\hline $\begin{array}{c}\text { Sample } \\
\text { number }\end{array}$ & Re, mg/kg & Se, $\mathrm{mg} / \mathrm{kg}$ & Hf, mg/kg & Yb, mg/kg & U, mg/kg & Fe, \% \\
\hline 1 & $0.232 \pm 0.032$ & $<0.2$ & $3.43 \pm 0.35$ & $1.01 \pm 0.13$ & $159 \pm 16$ & $0.247 \pm 0.048$ \\
\hline 10 & $1.27 \pm 0.14$ & $11.8 \pm 1.2$ & $2.52 \pm 0.25$ & $0.74 \pm 0.09$ & $131 \pm 13$ & $2.43 \pm 0.17$ \\
\hline 24 & $0.399 \pm 0.052$ & $<0.2$ & $6.73 \pm 0.67$ & $2.29 \pm 0.30$ & $215 \pm 22$ & $0.576 \pm 0.080$ \\
\hline 25 & $0.478 \pm 0.062$ & $<0.2$ & $9.40 \pm 0.94$ & $1.62 \pm 0.22$ & $191 \pm 19$ & $0.610 \pm 0.080$ \\
\hline 48 & $0.707 \pm 0.092$ & $<0.2$ & $3.43 \pm 0.37$ & $1.57 \pm 0.22$ & $251 \pm 25$ & $0.420 \pm 0.048$ \\
\hline 51 & $0.046 \pm 0.06$ & $40.8 \pm 4.9$ & $6.08 \pm 0.66$ & $1.38 \pm 0.14$ & $180 \pm 18$ & $0.309 \pm 0.048$ \\
\hline 73 & $2.90 \pm 0.30$ & $<0.2$ & $6.62 \pm 0.66$ & $4.10 \pm 0.45$ & $133 \pm 13$ & $2.23 \pm 0.17$ \\
\hline 81 & $0.95 \pm 0.12$ & $2.49 \pm 0.39$ & $14.5 \pm 1.4$ & $1.69 \pm 0.23$ & $162 \pm 16$ & $0.722 \pm 0.080$ \\
\hline 88 & $0.116 \pm 0.018$ & $<0.2$ & $4.50 \pm 0.45$ & $0.88 \pm 0.12$ & $219 \pm 22$ & $0.670 \pm 0.080$ \\
\hline 529 & $0.663 \pm 0.073$ & $8.51 \pm 0.77$ & $1.85 \pm 0.18$ & $1.02 \pm 0.13$ & $137 \pm 14$ & $0.459 \pm 0.048$ \\
\hline
\end{tabular}

To verify the noticed reverse dependence between rhenium and selenium contents a range of uranium ore samples from another two sites located in Chu-Sarysu and Syr Darya provinces were additionally investigated using the same approach. With rhenium mass fraction of the samples amounting to $0.65 \mathrm{mg} / \mathrm{kg}$, this relationship was confirmed. The whole pattern including all the studied samples is depicted graphically in Fig. 3 in regular and semi-logarithmic coordinates. LOI assessments were replaced by numerical values. To avoid negative magnitudes of common logarithms, selenium contents (in $\mathrm{mg} / \mathrm{kg}$ ) were multiplied by ten.

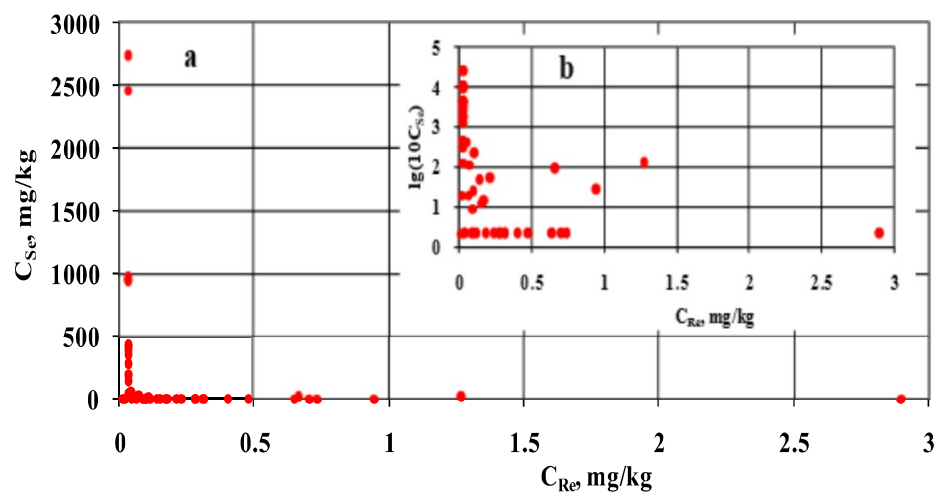

Figure 3 - Interrelation between rhenium and selenium contents in the uranium samples in regular (a) and semi-logarithmic (b) scales

As Figure 3 demonstrates the following prognostic feature may be apparently applied. Rhenium can not be obviously found in the samples characterized by very high selenium content, more than a hundred $\mathrm{mg} / \mathrm{kg}$. (It corresponds to 3 in Figure 3(b)). All the samples with selenium mass fraction lower than approximately $50 \mathrm{mg} / \mathrm{kg}$ are considered as relevant ones. Only these samples should be 
investigated by INAA. Preliminary screening can be carried out by a prompt method, i.e. XRF.

As this investigation revealed, high uranium content of the samples evidently presents main drawback for INAA. Neither of the elements (hafnium, selenium or any other) making unacceptable a coaxial type detector doesn't impede seriously rhenium determination in case a planar detector is applied. Several hundreds $\mathrm{mg} / \mathrm{kg}$ are apparently the uranium maximum content making possible conducting analysis under the conditions above (neutron flux density, sample mass, and irradiation time). The gained limit of rhenium identification in the investigated samples doesn't exceed $0.05 \mathrm{mg} / \mathrm{kg}$. This value corresponds to the accessed industrially significant rhenium content of complex ores as a by-product [30].

If uranium content is higher than $\approx 300 \mathrm{mg} / \mathrm{kg}$, as of the vast majority of the previewed samples, to implement INAA sample mass or irradiation time must be inevitably reduced. But this sharply diminishes sensitivity and accuracy of the methods. Beginning from some uranium content, preliminary rhenium concentration or radiochemical NAA can be the only option.

\section{Conclusion}

Comparator INAA using a planar type HPGe detector and iron as the internal standard proved its applicability to determine industrially significant contents of rhenium as a by-product in a part of uranium ore samples collected from Southern Kazakhstan uranium provinces. Distinct reverse correlation between rhenium and selenium mass fractions makes possible to apply XRF both for iron analysis and relevant sample selection to conduct INAA afterwards. Rhenium contents more than $(0.02-0.05) \mathrm{mg} / \mathrm{kg}$ are available for direct determinations if uranium mass fraction of the samples doesn't exceed several hundreds $\mathrm{mg} / \mathrm{kg}$. Otherwise, one or another way of uranium separation must be applied to realize NAA.

\section{Acknowledgments}

The work was supported by a grant from Ministry of Education and Sciences of the Republic of Kazakhstan (BR05236400).

\section{References}

1 Engalychev S.Yu. (2019) New data on the mineral composition of unique rhenium U-Mo-Re ores of the Briketno-Zheltukhinskoe deposit in the
Moscow basin. RAS [Doklady Akademii nauk], ser. geol., vol. 485(4), pp. 464-467. https://doi.org/ 10.31857/S0869-56524854464-467 (in Russian).

2 Trach G.N., Beskin S.M. (2011) Rhenium resources potential of the Russian territory. Prospect and Protection of Mineral Resources [Razvedka i ohrana nedr], vol. 6, pp. 26-33 (in Russian).

3 Troshkina I.D., Shilyaev A.B., Abdrakhmanov T.G., Maiboroda A.B. (2011) Rhenium in nontraditional raw materials: distribution and the possibility of recovery. Prospect and Protection of Mineral Resources [Razvedka i ohrana nedr], vol. 6, pp. 87-90 (in Russian).

4 Kremenetskiy A.A., Luneva N.V., Kulikova I.M. (2011) Belskoe Re-Mo-U deposit: mineralogical and geochemical characteristics, conditions of formation, technology of rhenium extraction. Prospect and Protection of Mineral Resources [Razvedka i ohrana nedr], vol. 6, pp. 33-41 (in Russian).

5 IAEA-TECDOC-1629 (2009) World Distribution of Uranium Deposits (UDEPO) with Uranium Deposit Classification. IAEA, Vienna. ISBN: 978-92-0-110509-7.

6 Sushko S.M., Shishkov I.A., Vershkov A.F. (2013) Uranium mining industry in Kazakhstan and the prospects for its development. News of the Academy of Sciences of RK, ser. geol. \& tech. sci., vol. 401(5), pp. 61-69 (in Russian).

7 Ministry of Industry and Infrastructural Development of the Republic of Kazakhstan. Committee of Geology and Subsoil Use. (accessed May 19, 2020) https://www.info.geology.gov.kz/ $\mathrm{ru} /$ informatsiya/spravochnik-mestorozhdenijkazakhstana/tverdye-poleznye-iskopaemye.

8 Evdokimova O.V., Pechishcheva N.V., Shunyaev K.Yu. (2012) Up-to-date methods for the determination of rhenium. J Anal Chem, vol. 67(9), pp. 741-753 https://doi.org/10.1134/ S1061934812090043.

9 Kolpakova N.A., Buinovskii A.S., Mel'nikova I.A. (2009) Determination of rhenium in goldcontaining ores by X-ray fluorescence spectrometry. $J$ Anal Chem, vol. 64(2), pp. 144-148. https://doi.org/10.1134/S1061934809020099.

10 Karadjov M., Velitchkova N., Veleva O., et al. (2016) Spectral interferences in the determination of rhenium in molybdenum and copper concentrates by inductively coupled plasma optical emission spectrometry (ICP-OES). Spectrochim Acta, Part B. vol. 119, pp. 76-82. https://doi.org/10.1016/ j.sab.2016.03.011.

11 Evdokimova O., Zaitceva P., Pechishcheva N.V., et al. (2014) The rhenium determination in 
copper and molybdenum ores and concentrates by ICP atomic emission spectrometry. Curr Anal Chem, vol. 10(4), pp. 449-456. https://doi.org/ 10.2174/157341101004140701102351.

12 Liu Y., Qi L., Gao J., Huang Z. (2016) Determination of rhenium and osmium by ICP-MS for galena and sphalerite. Acta Geochim, vol. 35(1), pp. 43-49. https://doi.org/10.1007/s11631-0150076-0.

13 Li J., Zhong L.-F., Xu J.-F., et al. (2014) Determination of PGE concentration(s) and Re-Os isotope(s) using ID-ICP-MS and N-TIMS from a single digestion after two-stage column separation. Geostand Geoanal Res, vol. 38(1), pp. 37-50. https://doi.org/10.1111/j.1751-908X.2013.00242.x.

14 Pearce C., Cohen A., Parkinson I. (2009) Quantitative separation of molybdenum and rhenium from geological materials for isotopic determination by MC-ICP-MS. Geostand Geoanal Res, vol. 33(2), pp. 219-229. https://doi.org/ 10.1111/j.1751-908X.2009.00012.x.

15 Swain K., Kayasth S. (2007) Preconcentration of traces of rhenium in geological matrix by NAA. J Radioanal Nucl Chem, vol. 271(1), pp. 129131. https://doi.org/1007/s10967-007-0118-0.

16 Wang H., Li J., Chen Y. (1992) Neutron activation analysis of rhenium in rocks after preliminary extraction with acetone. $J$ Radioanal Nucl Chem, vol. 161, pp. 227-231. https://doi. org/10.1007/BF02034895.

17 Zinovyev V.G., Ablesimov N.E., Egorov A.I., et al. (2017) Instrumental and radiochemical neutron activation analysis of the quartz adularia veins from the deposit Milogradovka, the Far East, Primorye. J Radioanal Nucl Chem, vol. 311(1), pp. 141-153. https://doi.org/10.1007/s10967-0164948-5.

18 Zinovyev V.G., Egorov A.I., Shulyak G.I., et al. (2016) Neutron activation analysis of the tagamite and suevite from the Kara astrobleme. $J$ Radioanal Nucl Chem, vol. 307(2), pp. 1315-1324. https://doi.org/10.1007/s10967-015-4480-z.

19 Dai X., Koeberl C., Fröschl H. (2001) Determination of platinum group elements in impact breccias using neutron activation analysis and ultrasonic nebulization inductively coupled plasma mass spectrometry after anion exchange preconcentration. Anal Chim Acta, vol. 436(1), pp. 79-85. https://doi.org/10.1016/S0003-2670(01)00902-3.

20 Silachyov I. (2016) Rare earths analysis of rock samples by instrumental neutron activation analysis, internal standard method. $J$ Radioanal Nucl Chem, vol. 310(2), pp. 573-582. https://doi.org/10.1007/s10967-016-4903-5.

21 Silachyov I. (2020) Elemental analysis of vegetation samples by INAA internal standard method. J Radioanal Nucl Chem, vol. 324(1), pp. 97-108. https://doi.org/10.1007/s10967-02007051-6.

22 Silachyov I. Yu. (2018) Determination of rare earths in uranium raw material by neutron activation analysis and X-ray fluorescence. News of the Academy of Sciences of RK, ser. chem. \& technol., vol. 429(3), pp. 28-38.

23 Koltochnik S.N., Sairanbayev D.S., Chekushina L.V., et al. (2018) Comparison of neutron spectrum in the WWR-K reactor with LEU fuel against HEU one. NNC RK Bulletin [Vestnik NYATS RK], vol. 76(4), pp. 14-17 (in Russian).

24 Kafala S.I., MacMahon T.D. (2007) Comparison of neutron activation analysis methods. $J$ Radioanal Nucl Chem, vol. 271(2), p. 507-516. https://doi.org/10.1007/s10967-007-0238-6.

25 Simonits A., De Corte F., Hoste J. (1976) Zirconium as a multi-isotopic flux ratio monitor and a single comparator in reactor-neutron activation. $J$ Radioanal Nucl Chem, vol. 31, pp. 467-586.

26 Nuclear data sub-committee. (accessed May $19,2020) k_{0}$-neutron activation analysis link page. http://www.kayzero.com/k0naa/k0naaorg/Links.html.

27 Hubbell J.H., Seltzer S.M. (accessed May $19,2020)$ X-ray mass attenuation coefficients. NIST standard reference database 126. https://www.nist.gov/pml/x-ray-mass-attenuationcoefficients (31.03.2020).

28 Kuzelman I., Fajgelj A. (2010) IUPAC/CITAC guide: Selection and use of proficiency testing schemes for a limited number of participants - chemical analytical laboratories. Pure Appl Chem, vol. 82(5), pp. 1099-1135. https://doi:10.1351/PAC-REP-09-08-15.

29 Vogelgesang J., Hädrich J. (1998) Limits of detection, identification and determination: a statistical approach for practitioners. Accred Qual Assur, vol. 3, pp. 242-255. https://doi.org/10.1007/s007690050234.

30 Samoilov A.G., Engalychev S.Yu., Zozyrev N.Yu., et al. (2018) Rhenium potential of the Upper Jurassic oil shale in the central part of the Volga Shale Basin. Regional Geology and Metallogeny [Regionalnaya geologiya i metallogeniya], vol. 75, pp. 67-78 (in Russian). 